Rehabilitation

An international, multidisciplinary journal http://informahealthcare.com/dre

ISSN 0963-8288 print/ISSN 1464-5165 online

Disabil Rehabil, Early Online: 1-4

(C) 2015 Informa UK Ltd. DOI: 10.3109/09638288.2015.1064482

\section{informa}

healthcare

\title{
REHABILITATION AND PRACTICE
}

\section{Lessons from the 2015 earthquake(s) in Nepal: implication for rehabilitation}

\author{
Phillip S. Sheppard ${ }^{1}$ and Michel D. Landry ${ }^{2,3}$ \\ ${ }^{1}$ Global Health Division, Canadian Physiotherapy Association, Ottawa, ON, Canada, ${ }^{2}$ Department of Physical Therapy Division, Duke University, \\ Durham, NC, USA, and ${ }^{3}$ Duke Global Health Institute, Duke University, Durham, NC, USA
}

\begin{abstract}
Purpose: There has been an increase in the number of natural disasters in recent history, and the rate of disability is increasing among survivors. The most recent major natural disaster was the earthquake(s) that occurred in Nepal on 25 April 2015 and 12 May 2015. In total, more than 8500 people were killed and over 18500 people were left injured. This article aims to demonstrate the role of rehabilitation professionals in post-disaster relief and beyond in Nepal. Method: This is an experiential account of physiotherapists present during the earthquake and participating in the post-disaster relief. Results: Rehabilitation professionals played an important role in the acute phase post-disaster by providing essential services and equipment. However, discharge planning emerged as an important role for rehabilitation providers in the early days of post-disaster and signaled a relatively new and innovative function that facilitated the heavy imbalance between little supply and tremendous demand for care. In the coming years, rehabilitation will need to support local initiatives that focus on minimizing the long-term effects among people with a newly acquired disability. Conclusions: Rehabilitation serves an important role across the continuum in post-disaster relief from the initial stages to the months and years following an event.
\end{abstract}

\section{> Implications for Rehabilitation}

- Driven by medical advances in acute field medicine, the relative proportion of casualties following natural disasters is decreasing, while relative rates of disability are rising among survivors.

- In post-disaster settings, the growing number of people with newly acquired disabilities will be added to the existing proportion of the population who lived with disabilities, creating a significant growth in the total number of people with disabilities (PWDs) in communities that are often ill prepared to provide necessary services.

- Rehabilitation interventions in the initial stages of emergency humanitarian response can minimize the long-term effects among people with newly acquired disabilities through early activation and prevention of secondary effects.

- Rehabilitation providers thus appear to have an important mediating effect on outcomes of disabilities in the early stages, but must also be strong partners with PWDs to advocate for social and political change in the long term.

\section{Keywords}

Disability, earthquake, Nepal, rehabilitation

\section{History}

Received 1 June 2015

Accepted 17 June 2015

Published online 13 July 2015

\section{Introduction}

Natural disasters are an integral part of human history and have been a large source of global mortality and morbidity rates. The number of such natural disasters is rising as evidenced by the findings of Leaning and Guha-Sapir, who reported that there were three times more disasters between the years 2000 and 2009, than there were between the years 1980 and 1989 [1]. Moreover, there

Address for correspondence: Dr Michel D. Landry, BScPT, PhD, Doctor of Physical Therapy Division, Duke University Medical Center, Box 104002, Durham, NC 27708, USA. E-mail: mike.landry@duke.edu have been over 200 million people, per year, since 1990, who have been affected by natural catastrophes around the world. While these staggering statistics may brush a bleak portrait, especially because we as the collective inhabitants of the planet may have had at least a partial role in promulgating these disasters though ecological and environmental "laissez-faire", survival rates of such tragedies have improved significantly over the years. Driven by important advances in emergency medical intervention, field medicine and infection control, people who have been injured in disasters are surviving at relatively higher rates [2]. However, many survivors are living with high rates of mental, emotional and physical disabilities directly or indirectly resulting from 
Figure 1. Much of Darbar Square of Hanuman Dhoka (Kathmandu, Nepal), a United Nations Educational, Scientific and Cultural Organization (UNESCO) World Heritage Site dating back more than 1700 years, lies in ruins following the 25 April 2015 earthquake [Photo: Michel Landry].

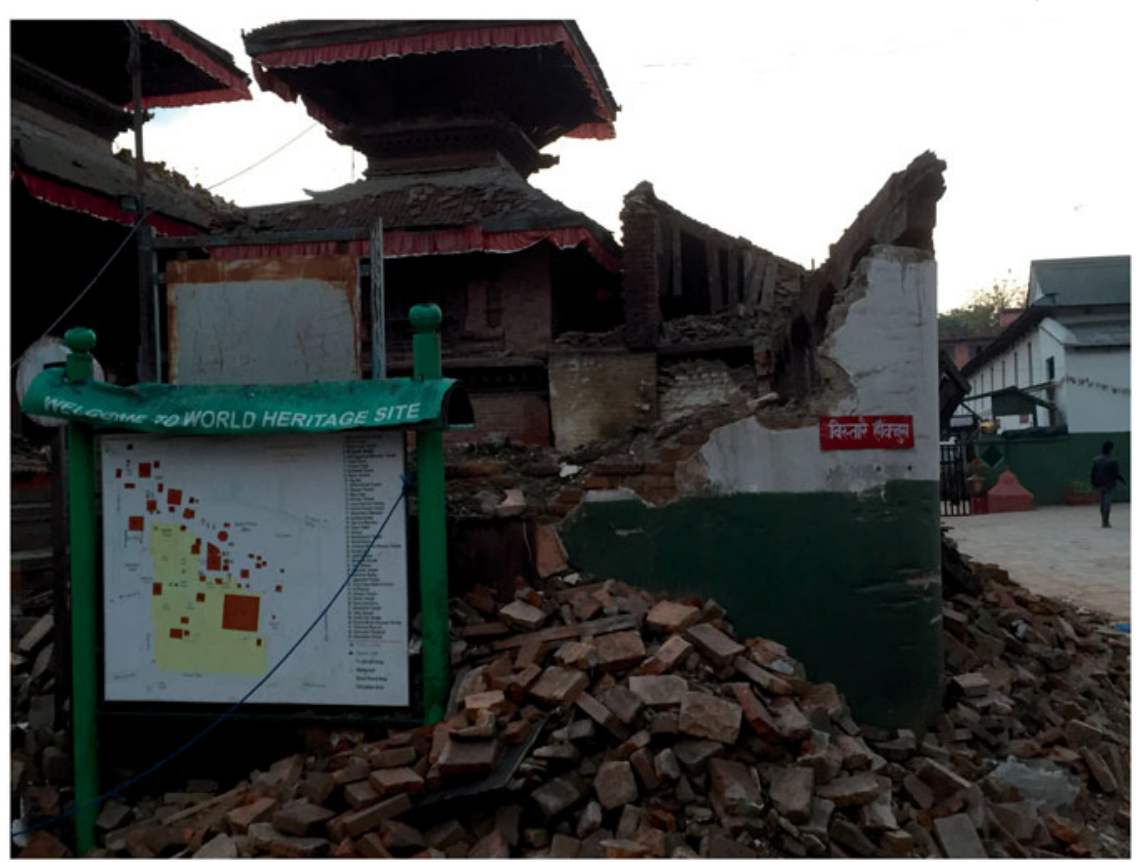

their injuries. It is our contention that over the last decade, we have witnessed an important transition from high proportional mortality to high morbidity rates in post-disaster zones.

The most recent major natural disaster has been the devastating earthquake in Nepal (Figure 1). This earthquake follows a long line of earthquakes over the past 5 years starting with Haiti (2010), Japan (2011), Philippines (2012), Pakistan (2013) and China (2014). The earthquake that occurred in Nepal on 25 April 2015 will most certainly alter the course of the small mountainous country, where a 7.8 magnitude earthquake struck the Lamjung district located $81 \mathrm{~km}$ North-west of the capital city of Kathmandu. More than 8500 people were killed and over 18500 individuals were injured in Nepal, and more than twodozen people are reported to have died in neighboring India, China and Bangladesh [3-5]. In total, over 750000 houses were destroyed or damaged as a result of the quake leaving hundreds of thousands homeless. This event was deemed the worst disaster to strike the region in over 80 years. After a few weeks of random after-shocks that drove people to seek safe shelter in streets and fields, a second major earthquake struck on 12 May 2015 causing still further damage. Non-Governmental Organizations (NGOs) already existing in the country were able to respond within hours of the earthquakes. As per the usual protocol, medical professionals were performing critical life saving procedures, rehabilitation professionals including occupational therapists, physiotherapists, and prosthetic and orthotic experts were providing assistance to hospitals in desperate need of equipment and human resources to meet the huge demand for services in the early phases of the disasters. In total, approximately 18500 people were injured in both major tremors, of them approximately $6 \%$ suffered spinal cord injuries (SCI), 2\% had amputations, 4\% sustained traumatic brain injuries (TBI), and the vast majority (approximately 70\%) of the injuries were fractured [6].

The day after the initial earthquake, the Nepalese government declared a state of emergency and issued a call for international aid. In the following days, international organizations poured into Nepal to provide life-saving medical care, food, water and emergency shelter. A Flash Appeal was issued for the Response to the Nepal Earthquake seeking \$423 million to support the relief operations for three months [3]. By 9 May, 330 humanitarian agencies were implementing more than 5100 humanitarian activities in the affected areas of Nepal [4]. In a blog posted by
The World Bank's Saurabh Dani, he stated that the poorest areas of Nepal were the hardest hit and that while parts of Kathmandu were severely impacted, the situation was "a rural disaster of huge proportions" [7]. Even though most of the destruction was in the surrounding areas, Kathmandu's infrastructure including the country's only international airport, made the capital city of the main logistics hub for the relief efforts. The difficulty in accessing remote areas left many villages without aid for days and even weeks following the initial earthquake, and while local groups organized relief efforts in Kathmandu to deliver essential items and basic medical services to remote villages by road and foot, extensive infrastructure damage limited the effectiveness of their work.

\section{Rehabilitation providers in the acute phase post-disaster}

Given collective experience from previous disasters, most notably Haiti, the acceptance for the role of rehabilitation providers is increasing in disaster response $[8,9]$. Hence, in the hours and days following the initial earthquake, local and international NGOs implementing various rehabilitation initiatives ranging from community-based rehabilitation (CBR) to disability advocacy quickly re-focused their work to provide assistance in the pre- and post-support of medical and surgical interventions among the injured. It was encouraging to see that many of the NGOs relied heavily on Nepalese human resources, such as physiotherapists and occupational therapists, to meet the increased demand for rehabilitation. Partnerships were quickly developed between local and international groups to further build capacity in rehabilitation, and provide care for acute trauma cases and specialized conditions, such as spinal cord injuries, amputations, acquired brain injuries and complex fractures. Physiotherapists and occupational therapists were deployed to the main hospitals in the capital and mobile teams were organized to provide assistance to hospitals and rehabilitation centers in the Kathmandu Valley and beyond. Patient tracking systems were semi-formalized in the initial days in order to adequately follow up and arrange care, particularly with people and children with newly acquired disabilities. International partners also supplied hospitals with mobility aids and assistive devices to increase independence and participation for those injured in the earthquakes. 
However, since the initial days of the disaster, the role of rehabilitation providers was not limited to treating the injured. Discharge planning emerged as an important role for rehabilitation providers in the early days of post-disaster and signaled a relatively new and innovative function that facilitated effective discharge, given the reality of the heavy imbalance between little supply and tremendous demand for care. In general, the vast majority of the injured were being medically evacuated from the affected zones and brought to Kathmandu. Once in the capital city, the injured were triaged and treated accordingly. However, the demand for care very soon outstripped the supply and there was a need to determine and implement ways in which to decompress the overflow of patients. A rate limiting factor for appropriate discharge was the extent to which a patient had a secure place to return to, and an understating of whether they could function safely. Rehabilitation providers became involved with discharge planning, especially among people with significant impairments, including but not limited to, spinal cord injury and traumatic brain injury. This function served two important outcomes: first, it provided a better trajectory of care for many patients who were medically stable and needed intense rehabilitation that they would not or could not have received in an acute setting, and second, it improved overall efficiency of the trauma centers because individual could be discharged quicker, opening up much needed acute care beds for the other injured.

In addition to facilitating discharge, rehabilitation providers began to teach other health care professionals about simple gait training and patient mobility techniques (i.e. log rolling) to reduce or minimize decubitus ulcers. Both local and international rehabilitation providers were able to effectively participate in functional mobility assessment and readiness for discharge, through teaching medical and hospital staff about criteria for safe discharge. Overall, the role of rehabilitation in those initial days was to assess and treat as many patients as possible, and to facilitate early and safe discharge to make room for others. However, engaging in discharge planning emerged as an important role for rehabilitation providers, which signaled a relatively new function that highlighted the value of rehabilitation in postdisasters relief efforts.

\section{Beyond the acute phase: moving forward in the long term}

As Nepal transitions from emergency relief to recovery and community development, the future needs for rehabilitation must focus on decreasing the impact of disability for the long term.

First, we suggest that international and local partners will need to continue to monitor the need for additional rehabilitation professionals in the event that more of the injured are transported from rural communities or more people are affected in the monsoon. Barring another sequential natural disaster in Nepal, the incidence of the injured have likely peaked from the initial tremors, but as people return to their villages to homes and building that are precariously unstable and unsafe, there is a high likelihood that people will re-enter these homes and sustain further traumatic injuries. We have been witnessing such secondary-injuries before in other disasters, and we will tragically likely see it again in Nepal, because at present there are few initiatives to identify, assess and demolish unsafe building across the country.

Second, we must seek ways to ensure that patients have some degree of appropriate access to rehabilitation services once they return to their communities. Nepal's infrastructure and healthcare is mainly focused on the large urban centers, while the majority of the damage occurred in rural areas. Partnerships will need to be developed with district hospitals and existing rehabilitation centers to create step-down facilities and ensure long-term rehabilitation needs are met. NGOs can provide human resources and specialized training on an as-needed basis, but ultimately to be sustainable, the local Nepali communities will need to advance this initiative. Where health centers are not available, temporary rehabilitation facilities can be a short-term solution. However, rehabilitation should immediately focus on sustainability and community development to ensure long-term solutions for the people affected. Various community development approaches, such as community-based rehabilitation (CBR) will be explored, as a strong and viable option for meeting rehabilitation needs in the future. In addition, the already existing specialized rehabilitation centers are working to increase their number of beds to accommodate for the increase in SCI, Amputations, TBI, and other neurological and complex conditions that will require ongoing care.

Finally, rehabilitation must focus on re-integration of individuals to their communities starting in the acute phase. This will be a difficult task as many communities and houses in Nepal were inaccessible for individuals with mobility aid or wheelchair prior to the earthquake: even in Kathmandu, the majority of buildings are inaccessible and the situation in rural communities is far worse. For instance, some communities have no road access and the only way to reach them is by hiking long distances through the mountains. Even if people who have a newly acquired disability manage to return to these communities, we must consider the quality of life of those individuals and the likelihood for further mental, emotional and physical health complications. Rehabilitation can contribute in solving this issue by improving function, independence and participation but ultimately it must be done along side people with disabilities themselves in order to be sustainable. Rehabilitation professionals should also be a strong advocate for accessible housing and infrastructure when Nepal begins to rebuild.

The experiences and lessons learned from previous disasters were applied prior to and after the earthquake in Nepal. The knowledge that Nepal was likely to be struck by an earthquake allowed local and international organizations to develop earthquake preparedness plans. This was evident in the timely response and dissemination of crucial equipment and knowledge in the initial hours following the event. As rehabilitation continues for the years to come, we need to focus on optimizing function and decreasing long-term disability. This dreadful event demonstrated the critical role for rehabilitation professionals in disaster response from the initial event to the months following. The tragic loss of human life and ancient heritage is staggering in Nepal, but we must now stand in solidarity to support the re-building process, so that all people regardless of ability or disability find their place in Nepal.

\section{Declaration of interest}

The authors report no declarations of interest.

\section{References}

1. Leaning J, Guha-Sapir D. Natural disasters, armed conflict, and public health. N Engl J Med 2013;369:1836-42.

2. Missair A, Pretto EA, Visan A, et al. A matter of life of limb? A review of traumatic injury patterns and anesthesia techniques for disaster relief after major earthquakes. Anesth Analg 2013;117: 934-41.

3. United Nations Office for the Coordination of Humanitarian Affairs (UNOCHA). Flash appeal for response to the Nepal earthquake. Available from: http://reliefweb.int/sites/reliefweb.int/files/ resources/nepal_flash_appeal.pdf [last accessed April-July 2015].

4. United Nations Office for the Coordination of Humanitarian Affairs (UNOCHA). Nepal: earthquake humanitarian snapshot. 
Available from: http://reliefweb.int/report/nepal/nepal-earthquakehumanitarian-snapshot-14-may-2015 [last accessed 14 May 2015].

5. United Nations Office for the Coordination of Humanitarian Affairs (UNOCHA). Nepal: earthquake 2015 situation report No. 16. Available from: http://reliefweb.int/report/nepal/nepal-earthquake2015-situation-report-no16-18-may-2015 [last accessed 18 May 2015].

6. World Health Organization and Nepal Ministry of Health and Population. Rehabilitation Cluster Report, Kathmandu, Nepal. 22 May 2015.
7. Dani S. The poorest are the hardest hit in rural Nepal. The World Bank blog - end poverty in South Asia. Available from: http:// blogs.worldbank.org/endpovertyinsouthasia/poorest-are-hardest-hitrural-nepal [last accessed 5 May 2015].

8. Landry MD, O'Connell C, Tardiff G, Burns AS. Post-earthquake Haiti: the critical role for rehabilitation services following a humanitarian crisis. Disabil Rehabil 2010;32:1616-18.

9. Merin O, Ash N, Levy G, et al. The Israeli field hospital in Haiti - ethical dilemmas in early disaster response. N Engl J Med 2010;362:e38. 